\title{
Assessment of Spatiotemporal Gait Parameters in Patients with Lumbar Disc Herniation and Patients with Chronic Mechanical Low Back Pain
}

\author{
Masoud AMIR RASHEDI BONAB ${ }^{1^{*}}$, Tugba KURU COLAK ${ }^{1 * *}$, Zafer Orkun TOKTAS ${ }^{2 *}$, Deniz KONYA ${ }^{2^{*}}$ \\ ${ }^{1}$ Marmara University, Faculty of Health Sciences, Physiotherapy and Rehabilitation Department, Istanbul, Turkey \\ ${ }^{2}$ Bahcesehir University Medical Faculty, Department of Neurosurgery, Istanbul, Turkey
}

Corresponding author: Zafer Orkun TOKTAS drzafertoktas@gmail.com

\section{ABSTRACT}

AIM: To assess spatiotemporal gait parameters in patients with lumbar disc herniation (LDH) and chronic mechanical low back pain (CMLBP), and compare with healthy control group.

MATERIAL and METHODS: A total of 70 patients was enrolled in this prospective, controlled cross-sectional study, of which 25 with LDH, 25 with CMLBP and 20 healthy individuals as the control group. Participants completed 10 passes on the "WIN-TRACK" Gait Analysis Platform at their self-selected walking speed. The arithmetic mean of the five flawless walking data was used for analysis. Pain intensity is assessed by the Visual Analog Scale (VAS).

RESULTS: The spatiotemporal gait parameters were significantly decreased in LDH and CMLBP groups than the healthy control group, particularly in LDH groups $(p \geq 0.001)$. It was found that pain intensity is negatively correlated to step and stride length, cadence and velocity $(p<0.001)$. Results of linear regression analysis showed that $10 \%$ of the changes in gait cycle duration of the left extremity and $74 \%$ of the changes in the velocity were associated with pain intensity.

CONCLUSION: Pain intensity can affect the spatiotemporal gait parameters in patients with Low Back Pain (LBP). Rehabilitation programs with gait optimization should be considered in the management of patients with LDH and CMLBP.

KEYWORDS: Lumbar disc herniation, Chronic mechanical low back pain, Spatiotemporal gait parameters, Pain, Gait analysis

\section{INTRODUCTION}

$\mathrm{L}$ ow back pain (LBP) is considered a major health problem worldwide. Epidemiological studies have indicated that the $65-80 \%$ of the world's population experiencing this problem at any given time in their lives as well as the $95 \%$ of this pain have been reported to be mechanical $(7,13,18)$. Many physical functions such as standing, sitting, traveling, walking, social life as well as sexual activities are compromised in patients with chronic LBP. Also, disability in daily life activities, health-related quality of life, and functional loss are the other consequences of chronic LBP $(16,22)$.

Many people with CMLBP suffer from walking difficulties and walk slower than healthy individuals. Preferred slower walking speed is an indicative feature of many gait disturbances and generally signals a poor motor control $(9,12,21)$. LDH is another common cause of LBP which results in lower extremity pain and numbness $(2,3)$. With $\mathrm{LDH}$ radiating the pain to the spine and legs, lower extremity functions in patients with CMLBP are affected (1,26-29).

Gait parameters are usually measured to obtain gait deviations and walking difficulties, make a diagnosis, determine appropriate therapy, monitor patient progress, and to determine the prognosis. The most common parameters selected for gait analysis are spatiotemporal parameters including stance duration, swing duration, double support duration, step length, stride length, walking speed (velocity),
Masoud AMIR RASHEDI BONAB (1) : 0000-0002-7875-0499 Tugba KURU COLAK (D) : 0000-0002-3263-2278
Zafer Orkun TOKTAS (10) : 0000-0002-5842-5891

Deniz KONYA (1) : 0000-0002-4263-6096 


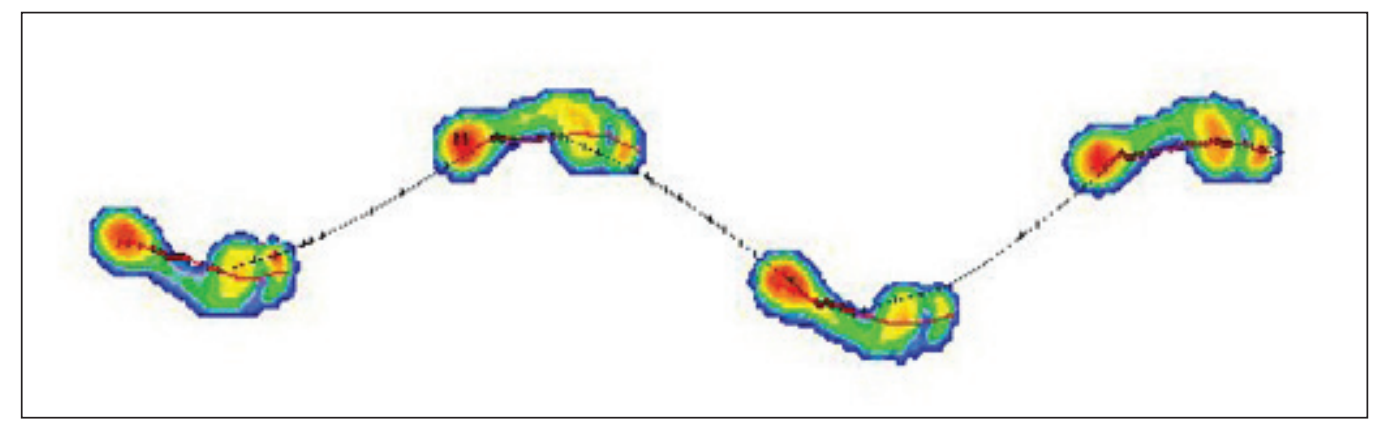

Figure 1: Pedobarographic and center of foot pressure.

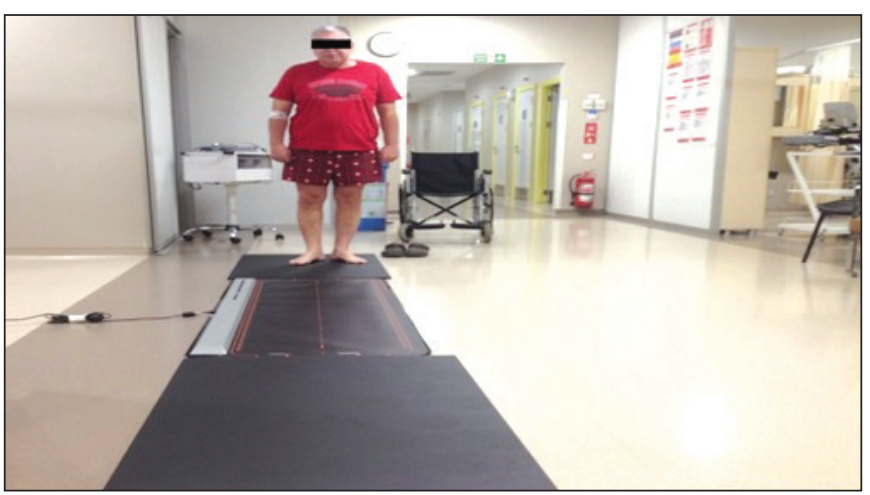

Figure 2: Analysis of spatiotemporal gait parameters on WinTrack platform.

and cadence $(5,20,23,24,30)$. Due to the discrete nature of alterations in gait characteristics, clinical observation may not be adequate in detecting small changes. Therefore, many technologies have been improved to assess the spatiotemporal gait parameters $(8,14)$. In this regard, this study aims to assess the spatiotemporal gait parameters in patients with $\mathrm{LDH}$ and CMLBP, and compare with healthy control group.

\section{MATERIAL and METHODS}

This study recruited patients diagnosed with LDH and CMLBP between March 2016 and August 2016 at Goztepe Medical Park Hospital, Brain and Spine Surgery Department. Prior to conducting the investigation, ethical clearance was obtained from the ethics committee of the Marmara University Institute of Health Sciences (protocol no. 28.03.2016-25), and informed consent was obtained from all participants.

The inclusion criteria for volunteers were as follows: (1) individuals admitted to the outpatient clinic with a complaint of back pain and the diagnosis of LDH or CMLBP by a specialist; (2) aged 25-65 years old; and (3) individuals who had experienced pain in the past 3 months. On the other hand, the exclusion criteria were: (1) individuals who had been receiving any treatment; (2) individuals with any congenital deformity in the spine or lower extremity; (3) previous surgery; (4) using assistive gait device; (5) balance problems due to any central nervous system disease; and (6) pregnancy.

The analysis of the pedobarographic and spatiotemporal gait parameters was performed using "WIN-TRACK" (Medi- capteurs, Balma, France) gait analysis platform system. The dimensions of this device are $1610 \mathrm{~mm} \times 652 \mathrm{~mm} \times 30 \mathrm{~mm}$ (length/width/height); the thickness of the platform is $9 \mathrm{~mm}$ composed of 12288 resistive type sensors. The dimensions of these sensors are $7.8 \times 7.8 \mathrm{~mm}^{2}$, and the acquisition frequency of the apparatus is up to 200 images/s enabling digitally recording the pedobarographic and spatiotemporal information of subjects' gait based on the center of foot pressure (Figure 1).

The participants were asked to continuously walk barefoot for ten times as straight as possible without any assistance on the WIN-TRACK platform within the same day (Figure 2). The five flawless walking data analyses of spatiotemporal gait parameters were recorded and the arithmetic means were computed for the five repetitions. Whenever they desired to take a rest, the patients were allowed to sit in a chair.

The following parameters were recorded for both extremities: step duration, gait cycle duration, double stance duration, swing duration, step length, gait cycle length, gait speed (velocity), and cadence.

The pain intensity was evaluated by a Visual Analog Scale (VAS). VAS is usually a horizontal line, $10 \mathrm{~cm}$ in length, anchored by word descriptors at each end with "No Pain" (score of zero) on the left side up to "pain as bad as it could be" or the "worst imaginable pain" (Score of 100 [100-mm scale]) on the right side. The patient was asked to mark the line point that represented his or her current pain $(6,19)$.

All Statistical analyses were performed using Statistical Package for Social Sciences (SPSS) version 20.0 (SPSS Inc., Chicago, IL, USA). P-values less than 0.05 were considered to be statistically significant for a two-tailed test. The chi-square test was used to compare the gender interaction between the groups. Normality was analyzed by the Kolmogorov-Smirnov test.

Demographic characteristics of all groups such as height, weight, and BMl were analyzed by one-way analysis of variance ANOVA test. Also, the age was analyzed by KruskalWallis test. One-way ANOVA test was employed for intergroup comparisons (LDH, CMLBP, Control) for step duration, gait cycle duration, swing duration, double stance duration, stride length, and step length. Similarly, Kruskal-Wallis test was used intergroup comparisons (LDH, CMLBP, Control) for velocity and cadence. Further, the independent t-test was utilized to compare between the two groups (LDH \& Control; CMLBP \& 
Control) for step duration, gait cycle duration, swing duration, double stance duration, stride length, step length. Likewise, Mann-Whitney $U$ test was employed to compare the means between the two groups (LDH \& Control; CMLBP \& Control) for velocity and cadence. Finally, the spearman correlation analysis was used to test the strength of the relationship between pain intensity and spatiotemporal gait parameters. Also, to evaluate the effect of pain on the spatiotemporal gait parameters, linear regression analysis was used.

\section{RESULTS}

Seventy patients were included in our study (39 females, 31 males), of whom 25 had LDH, 25 had CMLBP, and 20 where healthy individuals for the control group.
The mean pain score was 8.0 (range six to nine) for the patients with LDH and 5.7 (range four to eight) for patients with CMLBP. There was a significant difference between the two groups in terms of VAS scores $(p<0.001)$. The distribution of patients with LDH was as follows: one (4\%) patient at the level of L3-4, $14(56 \%)$ patients at the level L4-5, and 10 (40\%) patients at the level of L5-S1. However, no significant differences were detected between the groups concerning the demographic characteristic of the participants $(p>0.05)$ (Table I).

The temporal gait parameters were compared both between all groups (GI\&GII\&GIII) and two groups (GI\&GIII, GII\&GIII). There were significant differences between the groups in terms of temporal gait parameters $(p<0.05)$ (Table II).

Table I: Demographic Characteristics of the Participants

\begin{tabular}{lccc}
\hline & $\begin{array}{c}\text { LDH Group (n=25) } \\
\text { Mean } \pm \text { SD (min-max) }\end{array}$ & $\begin{array}{c}\text { CMLBP Group (n=25) } \\
\text { Mean } \pm \text { SD (min-max) }\end{array}$ & $\begin{array}{c}\text { Control Group (n=20) } \\
\text { Mean } \pm \text { SD (min-max) }\end{array}$ \\
\hline Age (years) & $\begin{array}{c}\text { (m) } \\
(25-65)\end{array}$ & $\begin{array}{c}43.7 \pm 14.5 \\
(25-65)\end{array}$ & $\begin{array}{c}39.6 \pm 8.3 \\
(27-56)\end{array}$ \\
\hline BMl $\left(\mathrm{kg} / \mathrm{cm}^{2}\right)$ & $26.50 \pm 3.50$ & $26.10 \pm 4.70$ & 0.300 \\
\hline Height $(\mathrm{m})$ & $(17.5-33.9)$ & $(19.5-34.7)$ & $24.10 \pm 4.50$ \\
& $1.70 \pm 0.09$ & $14.8-32.1)$ & 0.880 \\
\hline Male/Female & $(1.52-1.90)$ & $(1.50-1.89)$ & $1.71 \pm 0.06$ \\
$(1.55-1.84)$
\end{tabular}

LDH: Lumbar Dics Herniation, CMLBP: Chronic Mechanical Low Back Pain, BMI: Body Mass Index.

Table II: Distribution of the Temporal Gait Parameters in Groups

\section{LDH Group ( $n=25)$ Mean \pm SD (min-max)}

CMLBP Group ( $n=25)$ Mean \pm SD $(\min -\max )$
Control Group $(n=20)$ Mean \pm SD (min-max) p (GI\&GII\&GIII) (GI\&GIII) (GII\&GIII)

0.000 0.000 0.018

0.000 0.000 0.006 0,001 0.003 0.046 0.000 0.005

Double Stance

$0.46 \pm 0.12$

$0.36 \pm 0.07$

$0.31 \pm 0.04$

0.000

Duration (s) L

$(0.21-0.85)$

(0.23 - 0.51)

(0.23 - 0.39) 
Table II: Cont.

\section{LDH Group ( $\mathrm{n}=25)$ Mean \pm SD (min-max)}

CMLBP Group $(n=25)$ Mean \pm SD (min-max)
Control Group $(n=20)$

Mean \pm SD (min-max)
(GI\&GII\&GIII)

(GI\&GIII)

(GII\&GIII)

\begin{tabular}{|c|c|c|c|c|}
\hline $\begin{array}{l}\text { Double Stance } \\
\text { Duration (s) R }\end{array}$ & $\begin{array}{c}0.49 \pm 0.09 \\
(0.38-0.75)\end{array}$ & $\begin{array}{c}0.37 \pm 0.06 \\
(0.27-0.53)\end{array}$ & $\begin{array}{c}0.32 \pm 0.05 \\
(0.23-0.41)\end{array}$ & $\begin{array}{l}0.000 \\
0.000 \\
0.004\end{array}$ \\
\hline
\end{tabular}

*GI (LDH): Lumbar Dics Herniation, **GII (CMLBP): Chronic Mechanical Low Back Pain, ***GII: Control Group.

Table III: Distribution of the Spatial Gait Parameters in Groups

LDH Group $(\mathrm{n}=25)$
Mean \pm SD (min-max)

CMLBP Group $(\mathrm{n}=25)$

Mean \pm SD (min-max)
Control Group $(\mathrm{n}=20)$
Mean \pm SD $(\min -\max )$

(GI\&GII\&GII)

(GI\&GIII)

(GII\&GIII)

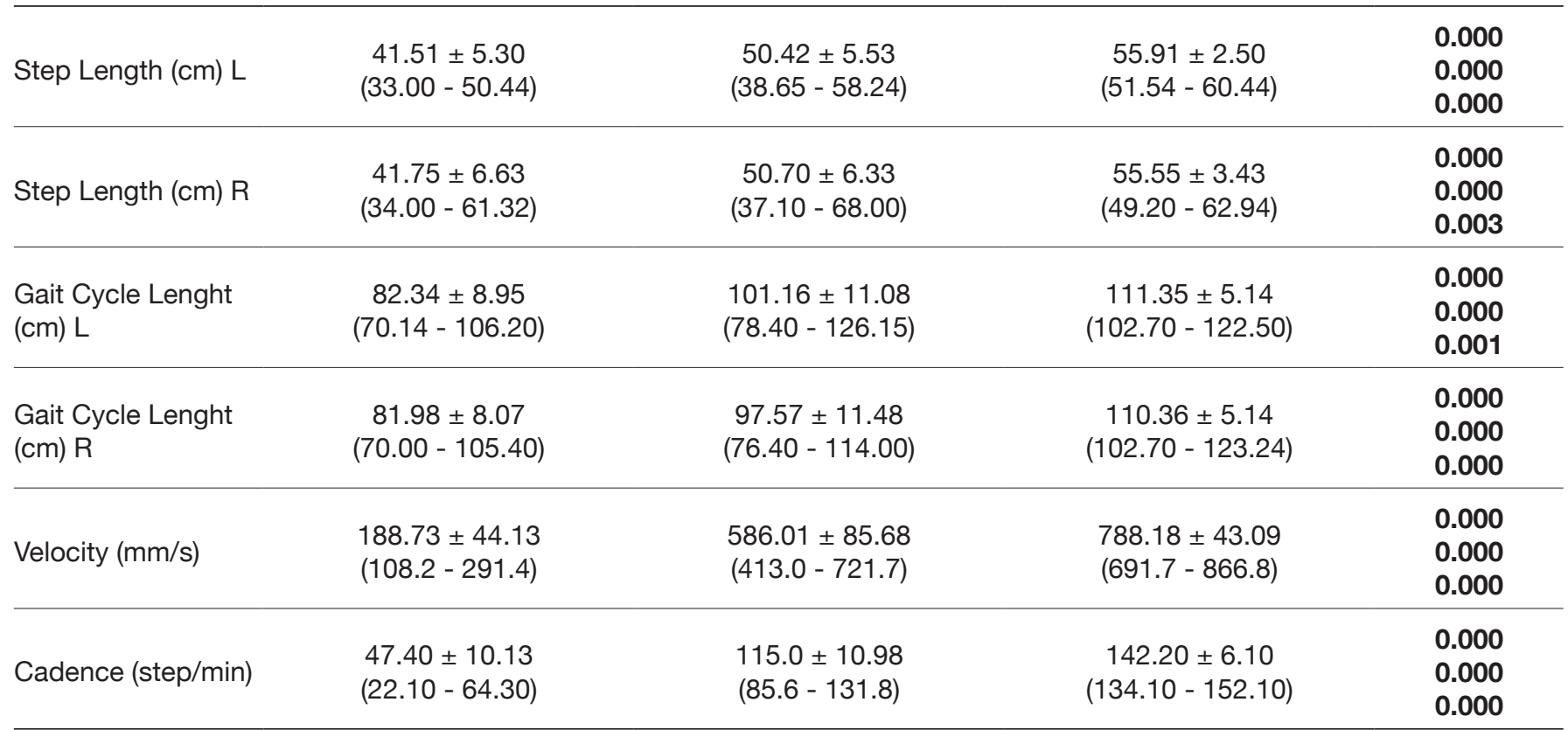

*GI (LDH): Lumbar Dics Herniation, **GII (CMLBP): Chronic Mechanical Low Back Pain, ** GIII: Control Group.

Similarly, the spatial gait parameters were also compared between all groups (GI\&GII\&GIII) and between two groups (GI\&GIII, GII\&GIII). There were also significant differences between the groups in terms of spatial gait parameters $(p<0.05)$ (Table III).

Next, the correlation between BMI and pain intensity as well as gait spatiotemporal parameters was examined across the groups. There were significant positive correlations between
BMI and the "bilateral step duration", "bilateral double stance duration" and "bilateral swing duration", among the temporal gait parameters $(\mathrm{p}<0.05)$. However, no statistical correlation was found between BMI and the other temporal gait parameters $(p>0.05)$ (Table IV). The correlation analysis revealed negative correlations between BMI and the "bilateral stride length", and "velocity" $(p<0.05)$. Eventually, no statistical correlation was detected between BMl and other temporal parameters ( $p>0.05)$ (Table V). 
Table IV: Correlation Analysis between BMI, Pain and the Temporal Gait Parameters

\begin{tabular}{|c|c|c|c|c|c|c|c|c|c|}
\hline \multirow{2}{*}{ n (70) } & & \multicolumn{2}{|c|}{ Step Duration (s) } & \multicolumn{2}{|c|}{ Gait Cycle Duartion (s) } & \multicolumn{2}{|c|}{$\begin{array}{c}\text { Double Stance } \\
\text { Duration (s) }\end{array}$} & \multicolumn{2}{|c|}{ Swing Duration (s } \\
\hline & & $\mathbf{L}$ & $\mathbf{R}$ & $\mathbf{L}$ & $\mathbf{R}$ & $\mathbf{L}$ & $\mathbf{R}$ & $\mathbf{L}$ & $\mathbf{R}$ \\
\hline \multirow[t]{2}{*}{$\mathrm{BMI}\left(\mathrm{kg} / \mathrm{cm}^{2}\right)$} & $r$ & ,249* & ,213* & $\begin{array}{l}114 \\
0358\end{array}$ & , 123 & ,275* &, $356^{* *}$ & ,273* &, $284^{*}$ \\
\hline & $\mathbf{p}$ & 0,038 & 0,047 & 0,358 & 0,333 & 0,026 & 0,004 & 0,022 & 0,017 \\
\hline \multirow{2}{*}{ Pain Intensity } & $\mathbf{r}$ &, $496^{\star \star}$ &, $525^{\star \star}$ &, $546^{* *}$ &, $530^{\star \star}$ & ,681** &, $664^{\star *}$ &, $586^{\star *}$ &, $592^{\star \star}$ \\
\hline & $p$ & 0,000 & 0,000 & 0,000 & 0,000 & 0,000 & 0,001 & 0,000 & 0,000 \\
\hline
\end{tabular}

*: Correlation is significant at the 0.05 level (2-tailed); **: Correlation is significant at the 0.01 level (2-tailed). BMI: Body Mass Index.

Table V: Correlation Analysis between BMI, Pain and the Spatial Gait Parameters

\begin{tabular}{|c|c|c|c|c|c|c|c|}
\hline \multirow{2}{*}{ n (70) } & & \multicolumn{2}{|c|}{$\begin{array}{l}\text { Step Length } \\
\text { (cm) }\end{array}$} & \multicolumn{2}{|c|}{$\begin{array}{l}\text { Gait Cycle Length } \\
\text { (cm) }\end{array}$} & \multirow[t]{2}{*}{$\begin{array}{l}\text { Velocity } \\
(\mathrm{mm} / \mathrm{s})\end{array}$} & \multirow[t]{2}{*}{$\begin{array}{l}\text { Cadence } \\
\text { (step/m) }\end{array}$} \\
\hline & & $\mathbf{L}$ & $\mathbf{R}$ & $\mathbf{L}$ & $\mathbf{R}$ & & \\
\hline $\mathrm{BMI}\left(\mathrm{kg} / \mathrm{cm}^{2}\right)$ & $\begin{array}{l}r \\
p\end{array}$ & $\begin{array}{l}-, 226 \\
0,061\end{array}$ & $\begin{array}{l}-, 202 \\
0,093\end{array}$ & $\begin{array}{l}-, 248^{*} \\
0,039\end{array}$ & $\begin{array}{c}-, 359^{\star *} \\
0,002\end{array}$ & $\begin{array}{l}-, 270^{*} \\
0,024\end{array}$ & $\begin{array}{l}-, 217 \\
0,071\end{array}$ \\
\hline Pain Intensity & $\begin{array}{l}r \\
p\end{array}$ & $\begin{array}{l}-, 735^{* *} \\
0,000\end{array}$ & $\begin{array}{l}-, 601^{* *} \\
0,000\end{array}$ & $\begin{array}{c}-, 730^{* *} \\
0,000\end{array}$ & $\begin{array}{c}-, 706^{* *} \\
0,000\end{array}$ & $\begin{array}{l}-, 898^{* *} \\
0,000\end{array}$ & $\begin{array}{l}-, 888^{* *} \\
0,000\end{array}$ \\
\hline
\end{tabular}

*: Correlation is significant at the 0.05 level (2-tailed); **: Correlation is significant at the 0.01 level (2-tailed). BMI: Body Mass Index.

We have obtained significantly positive correlations between the pain intensity and the "bilateral step duration", "bilateral gait cycle duration", and "bilateral swing duration" $(p<0.001)$. Additionally, a significantly strong positive correlation was found between the pain intensity and "bilateral double stance duration" ( $p \leq 0.001)$ (Table IV). There was, on the other hand, a strong negative correlation between the pain intensity and "bilateral step length" as well as "bilateral gait cycle length". Additionally, a highly significant strong negative correlation was found between pain intensity and "velocity" as well as "cadence" ( $p<0.01)$ (Table V).

The evaluation of pain intensity for spatiotemporal gait parameters (i.e., the dependent variable) was calculated by linear regression analysis.

There was a positive linear relationship between the pain intensity and temporal gait parameters. The pain intensity was associated with left step duration $(25 \%)(F=22.810 ; p<0.001)$; right step duration $(28 \%)(F=26.966 ; p<0.001)$; left gait cycle duartion (10\%) $(F=6.407 ; p=0.014)$; right gait cycle duartion $(15 \%)(F=10.696 ; p=0.002)$; left double stance duration $(34 \%)$ $(\mathrm{F}=32.812 ; \mathrm{p}<0.001)$; right double stance duration $(36 \%)$ $(F=35.029 ; p<0.001)$; left swing duration $(32 \%) \quad(F=31.227$; $\mathrm{p}<0.001)$; right swing duration $(32 \%)(\mathrm{F}=31.222 ; \mathrm{p}<0.001)$.

There was a statistically significant negative linear relationship between the pain intensity and spatial gait parameters. Finally, the pain intensity was associated with left step length (50\%) $(F=67.660 ; \quad p<0.001)$; right step length (35\%) ( $F=36.895$; $\mathrm{p}<0.001)$; left gait cycle length $(50 \%)(F=64.498 ; p<0.001)$; right gait cycle length $(\% 52)(F=74.660 ; p<0.001)$; cadence (70\%) $(\mathrm{F}=157.762 ; \mathrm{p}<0.001)$, and velocity $(74 \%)(\mathrm{F}=193.356$; $\mathrm{p}<0.001)$. The graphs of the linear regression are represented in Figure 3 for the highest and lowest values.

\section{DISCUSSION}

The aim of this study was to assess of spatiotemporal gait parameters in patients with LDH and CMLBP, and compare the parameters with healthy control group. To the best of our knowledge, this is the first study that compares gait parameters and determines to what extent does the pain intensity affects in patients with LDH and those with CMLBP. In comparison to the healthy control group, almost all the gait parameters were altered in both groups. Significantly, these changes were directly associated with pain intensity.

Our study supports previous findings reported by Cimolin et al. in 2011 who compared the spatiotemporal gait parameters in the stance phase, double support phase, the step length, and velocity between chronic LBP and healthy groups (10). Further, our study identified that other factors such as stance phase duration, bilateral double stance phase, bilateral step length, and velocity were substantially different between the mentioned groups. In contrast, we found a significant decreased in the cadence in patients with CMLBP group than the healthy group.

The results obtained by Gombatto et al in 2015 suggested that there is no statistically significant difference in bilateral gait cycle duration, bilateral step length, bilateral double step length, and velocity, and these gait parameters were similar between patients with LBP and healthy control group (15). On the contrary to Gombatto et al. in our study the difference in bilateral gait cycle duration, bilateral step length, bilateral 

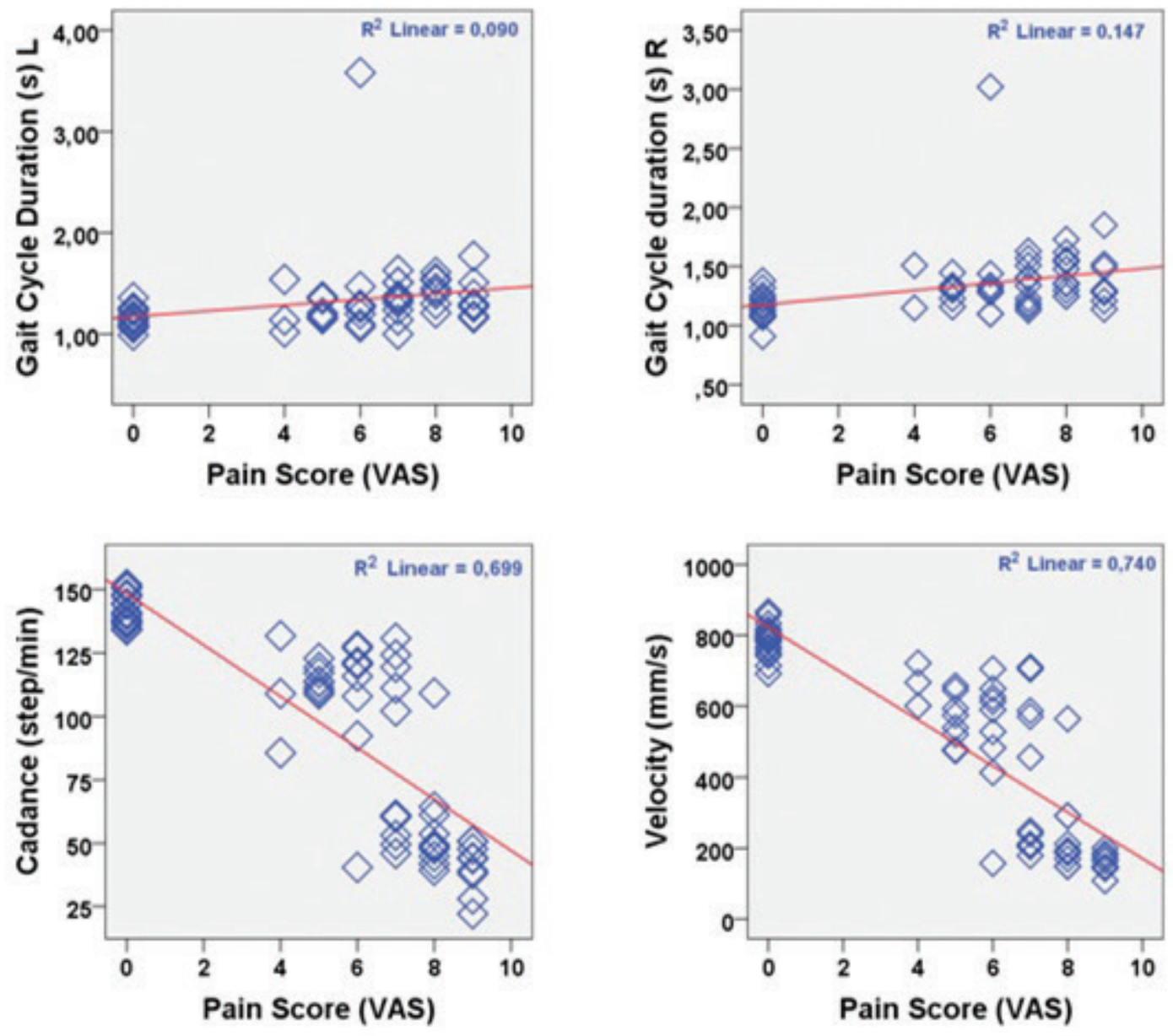

Figure 3: Linear regression analysis for the relationship between pain intensity and bilateral gait cycle duration, cadence and velocity.

double step length, and velocity was considerable between the groups. The patients with CMLBP had the longer gait cycle duration, shorter step length, shorter bilateral double step length, and less the velocity than the healthy control group. According to our experience and clinical observations, CMLBP causes the patient to change their gait and refrain from weight transfer to avoid exacerbation of the pain, resulting in a shorter step length of this extremity. In comparison to the literature, patients with CMLBP had a shorter step length and a higher mean velocity, but other gait parameters were similar (15).

Our findings are consistent with Hicks et al. in 2017 and Barzilay et al. in 2016 results showing in patients with chronic LBP had significant shorter step length, shorter stride length, greater stance times, longer periods of double support time and slower velocity than the healthy control group $(4,17)$.

In this study, LDH patients and CMLBP groups had significantly longer step duration, gait cycle duration, double stop duration, swing duration, shorter step length, gait cycle length, slower walking speed (velocity) and less in cadence than the healthy control group. Further, these differences were more between the LDH group and the healthy control group. The LDH patients try to minimize forces acting on the body which may cause pain and to avoid wide spine and lower extremity range of motion. Although these changes are a protective strategy, they negatively affect the objective gait parameters. This may cause different problems in patients in later periods.

According to the results o this research, there was a significant difference in both patient groups with comparing healthy control group in terms of spatiotemporal gait parameters.

The gait analysis by Papadakis et al. revealed gate variability attributed to the radicular pain in patients with lumbar spinal stenosis (25). The results by Conrad et al. indicated a weak positive correlation between pain intensity and velocity in lumbar spinal stenosis patients. However, they found no significant positive correlation between pain intensity and step length and cadence (11).

Overall, the present study revealed a strong correlation between pain intensity and temporal gait parameters. However, 
we found a considerable negative correlation between pain intensity and spatial gait parameters. In similar studies, little attention was paid to correlation analysis.

Notably, an inverse relationship was found between pain intensity and other factors such as velocity and cadence, explaining nearly $70 \%$ and $74 \%$ of the variance, respectively. The lowest variance was found at gait cycle duration $(R=15 \%$; $\mathrm{L}=10 \%$ ), and there was a positive linear relationship between pain intensity and gait cycle duration.

Although some research has been carried out on gait evaluation, much uncertainty still exists in this field. The key strength of our study was its large sample size with similar age ranges and BMI. The other advantages of our study included analyzing gait parameters quantitatively and comparing the results with healthy controls. In spite of the mentioned advantages, it has some limitations such as inaccessibility to 3D camera set and other forms of inquiry and inability to obtain kinetic and kinematic values. Also, forms of inquiry other than the visual analog scale were not used. Evaluation of physical activity levels of the patients and the fact that the gait habits of everyday life are not evaluated can be acceptable.

\section{CONCLUSION}

Since extremely little attention has been paid to quantification of gait characteristics, further research should be done on this topic. This paper attempted to assess the spatiotemporal gait alterations in LDH and CMLBP patients, and compare with healthy control group. A strong correlation was found between gait parameters and pain intensity. Therefore, in $\mathrm{LDH}$ and CMLBP patients priority should be given to pain treatment and after then gait pattern should be questioned, gait parameters should be evaluated, correct walking training and enhancing exercise approaches should be considered. Quantitative gait analysis could also be a useful method in efficient planning of rehabilitation programs after surgery, treatment optimization, and improving gait to achieve the desired treatment outcomes in patients with LDH and those with CMLBP. The results of the present study can be used in selecting better rehabilitation procedures after surgery and can provide a baseline for future interventional studies concerning mechanical low back pain and $\mathrm{LDH}$.

\section{ACKNOWLEDGEMENTS}

The authors acknowledge Dr. Suleyman Sener, and Dr. Mahsa Amir Rashedi Bonab for their invaluable contributions to this paper.

\section{CURRENT AFFILIATIONS}

*Bahcesehir University Medical Faculty, Department of Neurosurgery, Istanbul, Turkey.

**Marmara University, the Faculty of Health Sciences, Physiotherapy and Rehabilitation Department, Istanbul, Turkey.

\section{REFERENCES}

1. Andersson El, Lin CC, Smeets RJ: Performance tests in people with chronic low back pain: Responsiveness and minimal clinically important change. Spine 35:1559-1563, 2010

2. Andersson GB: Epidemiological features of chronic low-back pain. Lancet 354:581-585, 1999

3. Andersson GB, Brown MD, Dvorak J, Herzog RJ, Kambin P, Malter A, McCulloch JA, Saal JA, Spratt KF, Weinstein $\mathrm{JN}$ : Consensus summary of the diagnosis and treatment of lumbar disc herniation. Spine 21:75-78, 1996

4. Barzilay Y, Segal G, Lotan R, Regev G, Beer Y, Lonner BS, Mor A, Elbaz A: Patients with chronic non-specific low back pain who reported reduction in pain and improvement in function also demonstrated an improvement in gait pattern. Eur Spine J 25(9):2761-2766, 2016

5. Bilney $\mathrm{B}$, Morris $\mathrm{M}$, Webster $\mathrm{K}$ : Concurrent related validity of the GAITRite walkway system for quantification of the spatial and temporal parameters of gait. Gait Posture 17:68-74, 2003

6. Boonstra AM, Schiphorst PHR, Reneman MF, Posthumus JB, Stewart RE: Reliability and validity of the visual analogue scale for disability in patients with chronic musculoskeletal pain. Int J Rehabil Res 31:165-169, 2008

7. Borenstein DG, Wiesel SW, Boden SD: Clinical evaluation of low back pain. In: Waldman SD (ed), Low Back Pain Medical Diagnosis and Comprehensive Management. Philadelphia: WB Saunders Company, 1995:63-217

8. Bridenbaugh SA, Kressig RW: Laboratory review: The role of gait analysis in seniors' mobility and fall prevention. Gerontology 57:256-264, 2011

9. Buzzi UH, Stergiou N, Kurz MJ, Hageman PA, Heidel J: Nonlinear dynamics indicates aging affects variability during gait. Clin Biomech 18:435-443, 2003

10. Cimolin V, Vismara L, Galli M, Zaina F, Negrini S, Capodaglio P: Effects of obesity and chronic low back pain on gait. J Neuroeng Rehabil 8:55, 2011

11. Conrad BP, Shokat MS, Abbasi AZ, Vincent HK, Seay A, Kennedy DJ: Associations of self-report measures with gait, range of motion and proprioception in patients with lumbar spinal stenosis. Gait Posture 38:987-992, 2013

12. Dingwell JB, Cavanagh PR: Increased variability of continuous overground walking in neuropathic patients is only indirectly related to sensory loss. Gait Posture 14:1-10, 2001

13. Felson DT: Epidemiology of the rheumatic diseases. In: Koopman WJ, McCarty DJ (ed), Arthritis and Allied Conditions Baltimore. Williams \& Wilkins, 1997:3-34

14. Gillain S, Petermans J: Contribution of new techniques to study the gait in old populations. Ann Phys Rehabil Med 56:384-395, 2013

15. Gombatto SP, Brock T, DeLork, Glynis Jones A, Madden E, Rinere C: Lumbar spine kinematics during walking in people with and people without low back pain. Gait Posture 42:539544,2015 
16. Hasanefendioglu EZ, Sezgin M, Sungur MA, Cimen OB, Incel NA, Sahin G: Health-related quality of life in patients with chronic low back pain: Effects of pain, clinical and functional status on quality of life. Journal of Phsical Medicine \& Rehabilitation Sciences 58:93-98, 2012

17. Hicks GE, Sions JM, Coyle PC, Pohlig RT: Altered spatiotemporal characteristics of gait in older adults with chronic low back pain. Gait Posture 55:172-176, 2017

18. Isaac Z, Katz JN, Borenstein DG: Regional and Widespread pain: Lumbar spine disorders. In: Hochberg MC, Silman AJ, Smolen JS, Weinblatt ME, Weisman MH (ed), Rheumatology. Oxford: Elsevier, 2008:593-618

19. Jensen MP, Karoly P, Braver S: The measurement of clinical pain intensity: A comparison of six methods. Pain 27:117-126, 1986

20. Judge JO, Underwood M, Gennosa T: Exercise to improve gait velocity in older persons. Arch Phys Med Rehabil 74:400406, 1993

21. Kwakkel G, Wagenaar RC: Effect of duration of upper- and lowerextremity rehabilitation sessions and walking speed on recovery of interlimb coordination in hemiplegic gait. Phys Ther 82:433-448, 2002

22. Manchikanti L, Derby R, Wolfer L, Singh V, Datta S, Hirsch JA: Evidence-based medicine, systematic reviews, and guidelines in interventional pain management. Pain Physician 12:929963, 2009
23. McDonough AL, Batavia M, Chen FC, Kwon S, Ziai J: The validity and reliability of the GAITRite system's measurements: A preliminary evaluation. Arch Phys Med Rehabil 82:419-425, 2001

24. Mudge S, Stott NS: Outcome measures to assess walking ability following stroke: A systematic review of the literature. Physiotherapy 93:189-200, 2007

25. Papadakis NC, Christakis DG, Tzagarakis GN, Chlouverakis Gl, Kampanis NA, Stergiopoulos KN, Katonis PG: Gait variability measurements in lumbar spinal stenosis patients: Part A. Comparison with healthy subjects. Physiol Meas 30:1171-1186, 2009

26. Rosomoff HL, Fishbain DA, Goldberg M, Santana R, Rosomoff RS: Physical findings in patients with chronic intractable benign pain of the neck and/or back. Pain 37:279-287, 1989

27. Taylor NF, Evans OM, Goldie PA: The effect of walking faster on people with acute low back pain. Eur Spine J 12:166-172, 2003

28. Teixeira da Cunha-Filho I, Lima FC, Guimarães FR, Leite HR: Use of physical performance tests in a group of Brazilian Portuguese-speaking individuals with low back pain. Physiother Theory Pract 26: 49-55, 2010

29. Van der Valk RWA, Dekker J, van Baar ME: Physical therapy for patients with back pain. Physiotherapy 81:345-351, 1995

30. Waite LM, Broe GA, Grayson DA, Creasey H: Motor function and disability in the dementias. Int J Geriatr Psychiatry 15:897903, 2000 